\title{
PENDIDIKAN KARAKTER NASIONALIS-RELIGIUS BAGI MAHASISWA PENDIDIKAN BAHASA INDONESIA DI UNIVERSITAS JEMBER STUDI KASUS
}

\author{
Sukatman, Furoidatul Husniah, Akhmad Taufiq, Endang Sri Widayati, Anita Widjajanti, \\ Siswanto, dan Fitri Nura Murti.

\section{Universitas Jember}

sukatman.fkip@unej.ac.id; furoidatulhusniah@gmail.com; akhmadtaufiq1@gmail.com; endangsri.fkip@unej.ac.id; maduwangi@gmail.com; fitri.fkip@unej.ac.id

Diterima: 27 November 2018

Publikasi: 27 Februari 2019

DOI: http://dx.doi.org/10.32528/bb.v4i1.1872

\begin{abstract}
ABSTRAK
Penguatan ketahanan nasional dapat dilakukan dengan pembinaan mentalideologi kebangsaan. Kegiatan tersebut mendesak untuk dilakukan karena di Indonesia marak semangat mikro-etnis nasionlisme dan ideologi fundamentalis anti Pancasila yang berpoteni memecah belah negara. Salah satu upaya penguatan ketahan nasional itu adalah pendidikan karakter nasionalis-religius. Pendidikan tersebut menjadi tanggung jawab lembaga-lembaga pendidikan, termasuk perguruan tinggi. Kajian ini memaparkan upaya pendidikan karakter nasionalisreligius pada program studi Pendidikan Bahasa Indonesia. Penelitian dilaksanakan dengan rancangan kualitatif dengan menggunakan pendekatan multidisipliner yakni pendidikan, kebudayaan, ketahanan nasioanal. Sasaran penelitian berupa pendidikan karakter nasionali-religius pada program studi pendidikan bahasa Indonesia di Universitas Jember. Data dialisis dengan menggunakan metode kualitatif-multidipliner. Hasil penelitian menunjukkan pendidikan karakter nasionalis-religius untuk mahasiswa Pendidikan Bahasa Indonesia di Universitas Jember terdapat pada (1) rencana pembelajaran yaitu pada (a) standard pembelajaran karakter, (b) "learning outcome" program studi, dan (c) silabus matakuliah, (2) materi ajar, dan (3) proses pembelajaran. Sementara, evaluasi pembelajaran masih kurang menekankan pendidikan karakter nasionalis-religius. Masih terdapat mahasiswa yang cenderung "coba-coba atheis" 0,025\% dan cenderung religius-radikal $1 \%$. Untuk mengatasi hal negatif tersebut mahasiswa, program studi, dan universitas perlu bekerjasama secara terpadu.
\end{abstract}

Kata Kunci: mahasiswa, pendidikan karakter, nasionalisme-religius

\begin{abstract}
National character education for the young generation of Indonesia is urgent to do because of the rise of the national micro-ethnic spirit and the anti-Pancasila fundamentalist ideology that can divide the country. National-religious character education is the responsibility of educational institutions, including universities. This study aims to explain the efforts of the Indonesian Language Education study program to instill nationalist-religious character. The research was conducted with a qualitative- multidisciplinary design. The research target was national-religious character education in the Indonesian language education program at the University of Jember. Data were analyzed using interactive flow models. The results of the study show that national- religious character education for students is in the learning plan on the elements of character learning standards, study program learning outcomes,
\end{abstract}


and course syllabus. The content of religious-nationalist characters is also found in teaching material and the learning process. In the evaluation section, learning still lacks emphasis on religious-nationalist character education. There are students who tend to "try atheists"

$0.025 \%$ and those who tend to be religious-Islamic radical $1 \%$. To overcome this negative problem, students, study programs and universities need to collaborate in an integrated manner.

Key word: student, character education, nasionalisme-religius

\section{PENDAHULUAN}

Penguatan ketahanan nasional dapat dilakukan dengan pembinaan mental-ideologi kebangsaan, penataan lembaga kenegaraan yang sesuai dengan UUD 1945, penataan infrastruktur politik yang sesuai dengan koridor kebangsaan, pengembangan sumber Daya Manusia, dan pemerataan pembangunan ke seluruh wilayah Indonesia. Pembinaan mental ideologi kebangsaan mendesak untuk dilakukan di Indonesia karena munculnya persaingan antarbangsa, menyebarnya ideologi bangsa lain yang bertentangan dengan sistem kenegaraan Indonesia, maraknya semangat mikro- etnis nasionlisme yang berpoteni memecah belah negara, dan berkembangnya ideologi fundamentalis anti Pancasila yang mengancam persatuan bangsa.

Masih segar dalam memori bangsa Indonesia tentang adanya Gerakan Aceh Merdeka, Organisasi Papua Merdeka, lepasnya Timor Timor dari Indonesia, kasus Poso di Sulawesi, dan organisasi ekstrem kanan yang anti Pancasila. Peledakan fasilitas ibadah, hotel, dan gedung kepolisian oleh teroris membuktikan bahwa radikalisme betul- betul mengancam ketahanan negara. Penelitian Badan Intelijen Negara
(2017) mengungkap 39\% mahasiswa Indonesia terpapar faham radikal (Liputan6.com 29 April 2018). Ini sebuah fakta yang membahayakan bagi keberlangsungan negara Indonesia.

Permasalah yang muncul terkait ketahanan ideologi di Indonesia ada dua kelompok besar. Pertama, rasa nasionalisme cenderung membelok ke atheisme yang bertentangan dengan sila Ketuhanan Yang Mahaesa, seperti gerakan komunisme seperti PKI. Walaupun kelompok ini cinta Indonesia tetapi fahamnya anti agama sehingga bertentangan dengan Pancasila. Kelompok ini berfaham nasionalis-atheis. Kedua, rasa keagamaan yang kuat pada kelompok agama Islam akan tetapi ada kecenderungan mengganti Pancasila, seperti gerakan Negara Islam Indonesia. Gerakan ini mengancam persatuan bangsa karena kelompok agama lain merasa dikesampingkan. Kelompok ini berfaham religiusradikal. Dua faham di atas banyak memunculkan masalah dan idealnya bangsa Indonesia berpikiran nasionalis-religius atau religiusnasionalis.

Pendidikan karakter nasionalis-religius menjadi tanggung jawab lembaga pendidikan, termasuk 
perguruan tinggi. Salah satu upaya yang dapat dilakukan untuk membangun ketahanan nasional pada bidang mental-ideologi adalah pendidikan karakter kebangsaan di sekolah dasar sampai perguruan tinggi. Upaya ini telah lama dilakukan, akan tetapi hasilnya masih belum maksimal.

Kajian ini berupaya memaparkan gambaran pendidikan karakter nasionalis- religius atau religiusnasionalis yang bagi mahasiswa Program Pendidikan Bahasa Indonesia di Universitas Jember. Kajian ini berfokus pada rencana pembelajaran, materi ajar, proses, dan evaluasi pembelajaran. Hasil kajian ini diharapkan dapat bermanfaat untuk refleksi pendidikan, khususnya untuk meningkatkan kualitas pendidikan karakter di perguruan tinggi.

Kajian Teori Sejarah, ideologi, dan ketahanan nasional. Sejarah merupakan peristiwa yang terjadi pada masa lampau dan menjadi pengalaman yang kemudian dipelajari agar memperoleh manfaat bagi kehidupan sekarang dan mendatang. Dengan belajar sejarah, manusia akan memperoleh nilai positif yang perlu diteruskan dan dikembangkan, sedangkan nilai negatif ditinggalkan untuk menentukan arah generasi sekarang dan mendatang dalam membangun negaranya. Sejarah bukan sekedar masa lalu karena sejarah memiliki kesinambungan antara masa lalu, sekarang, dan masa yang datang. Sejarah dipahami sebagai masa lampau yang belum selesai. Sejarah menekankan aspek kelampauan, tetapi memiliki pengaruh untuk perbaikan masa depan yang lebih baik.

\section{Menurut}

Kartodirjo sejarah mempunyai fungsi genetis dan didaktik. Fungsi genetis maksudnya, nilai-nilai luhur yang terdapat di dalam setiap sejarah diwariskan secara turun temurun agar dapat membentuk watak generasi sesuai dengan harkat dan martabatnya. Fungsi didaktik yaitu nilai luhur yang terdapat pada sejarah dapat digunakan untuk mengembangkan seluruh potensi generasi muda sehingga mampu memberikan pelajaran hidup.

Optimalisasi fungsi sejarah untuk pembangunan masa depan memerlukan kesadaran sejarah. Kesadaran sejarah akan menunjukkan satu tingkat penghayatan bahwa masa lalu merupakan tuntunan untuk menghadapi masa kini dan mendatang. Refleksi diri yang berkesinambungan berdasarkan kesadaran sejarah menjadi sangat penting, karena kesadaran sejarah merupakan orientasi intelektual dan sikap jiwa untuk memahami kepribadian nasional secara tepat (Soedjatmoko, 1986:66-67).

Usaha untuk mencapai kesadaran sejarah perlu dilakukan terus menerus agar "pemitosan" dan penggiringan sejarah untuk kepentingan pribadi atau kelompok tidak terjadi. Karena itu perlu diciptakan kondisi yang kondusif untuk mendorong proses belajar dari sejarah secara benar. Karena setiap generasi menghadapi tuntutan zaman 
yang berbeda, maka proses pemaknaan sejarah bagi generasi baru perlu adanya pewarisan (Widja, 2002:10-11).

Pewarisan ideologi dalam kontek negara bangsa sama halnya dengan pewarisan nilai budaya bangsa. Pewarisan nilai budaya dalam menjaga eksistensi bangsa dan negara penting, karena nilai atau ideologi adalah salah satu faktor terciptanya ketahanan nasional.

Pembinaan ideologi dilakukan untuk mencapai kekuatan nasional yang dilakukan secara menyeluruh dan integral dalam berbagai aspek kehidupan, yaitu ideologi, politik, ekonomi, sosial budaya dan hankam. Pembinaan ideologi dilakukan sebagai prioritas dalam ketahanan nasional.

Ketahanan nasional adalah kondisi dinamis Indonesia yang berisi keuletan dan ketangguhan kekuatan nasional dalam menghadapi serta mengatasi segala tantangan, ancaman, hambatan dan gangguan yang datang dari luar maupun dari dalam, secara langsung atau tidak langsung membahayakan kehidupan bangsa Indonesia (Pidato Kenegaran Presiden 16 Agustus 1975). Untuk mewujudkan ketahanan sosial budaya warga negara Indonesia memerlukan kehidupan yang (a) beriman dan bertakwa kepada Tuhan Yang Maha Esa, (b) rukun, bersatu, dan cinta tanah air, (c) maju dan sejahtera dalam kehidupan yang serba selaras, (d) serasi dan seimbang serta mampu menangkal penetrasi budaya asing yang tidak sesuai dengan kebudayaan nasional.

Kearifan lokal berfungsi sebagai pencegah konflik sosial dan kenegaraan yang memperkuat ketahanan nasional. Setiap kebudayaan daerah mengandung kearifan lokal yang berfugsi untuk menetralkan pengaruh negatif budaya asing. Kebudayaan nasional merupakan hasil interaksi antara budaya daerah dengan budaya asing yang kemudian diterima sebagai nilai bersama seluruh bangsa. Interaksi budaya sebaiknya berjalan secara wajar dan alamiah tanp unsur paksaan dan dominasi budaya terhadap budaya lainnya (Kayudha,2013).

Pembangunan nasional dalam konteks menuju masyarakat madani dapat menggunakan ukuran sebagai berikut. Terpeliharanya eksistensi agama atau ajaran-ajaran yang ada dalam masyarakat. Terjaminnya keamanan, ketertiban, dan keselamatan. Tegaknya kebebasan berpikir yang jernih dan sehat. Terbangunnya situasi kekeluargaan yang tenang dan tenteram dengan penuh tenggang rasa. Terbangunnya kondisi daerah yang demokratis, santun, dan bermoral tinggi. Terbangunnya kesejahteaan sosial ekonomi masyarakat (Puguh, 2009).

Dari beberapa konsep tentang kesejarahan, ideologi dan ketahanan nasional di atas, dapat dipahami bahwa pelestarian nilai budaya dan pemertahanan identitas nasional berdasarkan kearifan lokal dapat digunakan sebagai landasan 
pembangunan ketahanan nasional dalam bidang budaya yang menjadi perekat integrasi NKRI. Kearifan lokal merupakan filter yang mengadaptasi dan mengeliminasi nilai-nilai negatif yang tidak sesuai dengan budaya bangsa. Harapannya jati diri bangsa tidak melemah dan hilang di tengah arus budaya global yang terus dipaparkan lewat berbagai cara dan media.

\section{Pendidikan}

nasionalis-religius atau karakter nasionalis merupakan religiusupaya membangun ketahanan nasional pada bidang ideologi dan budaya pada umumnya. Kerangka Kualitas Nasional Indonesia yang diundangkan oleh pemerintah Republik Indonesia menjadi standard karakter setiap lulusan perguruan tinggi. Pedoman itu telah dibakukan secara jelas dalam Peraturan Presiden RI No 8 tahun 2012 (Presiden RI, 2012). Enam karakter umum tersebut mencakup hal-hal sebagai berikut. (1) Bertaqwa kepada Tuhan Yang Maha Esa. (2) Memiliki moral, etika dan kepribadian yang baik di dalam menyelesaikan tugasnya. (3) Berperan sebagai warga negara yang bangga dan cinta tanah air serta mendukung perdamaian dunia. (4) Mampu bekerja sama dan memiliki kepekaan sosial dan kepedulian yang tinggi terhadap masyarakat dan lingkungannya. (5) Menghargai keanekaragaman budaya, pandangan, kepercayaan, dan agama serta pendapat/temuan original orang lain. (6) Menjunjung tinggi penegakan hukum serta memiliki semangat untuk mendahulukan kepentingan bangsa serta masyarakat luas.

Pendidikan tidak hanya membentuk insan Indonesia yang cerdas, tetapi juga menciptakan manusia yang berkepribadian atau berkarakter, sehingga akan lahir generasi bangsa yang tumbuh berkembang dengan karakter luhur bangsa, cinta tanah air, dan cinta agama. Pikiran ini selaras dengan Lickona (2013:3-36) bahwa pendidikan bukan hanya membuat anak cerdas tetapi juga bermoral dan berkelakuan baik. Enam nilai karakter kebaikan tersebut dalam pembahasan ini dirangkum dalam tema "pendidikan karakter nasionalis-religius".

Karakter nasionalis merupakan cara berpikir, bersikap, dan berbuat yang menunjukkan kesetiaan, kepedulian, dan penghargaan yang tinggi terhadap bahasa, lingkungan fisik, sosial, budaya, ekonomi, politik bangsa, dan menempatkan kepentingan negara di atas kepentingan diri dan kelompoknya. Sikap nasionalis ditunjukkan melalui sikap apresiasi budaya bangsa sendiri, menjaga kekayaan budaya bangsa, rela berkorban, unggul, dan berprestasi, cinta tanah air, menjaga lingkungan, taat hukum, disiplin, menghormati keragaman budaya, suku, dan agama.

Karakter religius mencerminkan keberimanan terhadap Tuhan yang Maha Esa. Karakter ini diwujudkan dalam perilaku (a) melaksanakan ajaran agama dan kepercayaan yang dianut, (b) menghargai perbedaan agama, (c) menjunjung tinggi sikap 
toleran terhadap pelaksanaan ibadah agama dan kepercayaan lain, dan (d) hidup rukun dan damai dengan pemeluk agama lain. Implementasi nilai karakter religius ini ditunjukkan dalam sikap cinta damai, toleransi, menghargai perbedaan agama dan kepercayaan, teguh pendirian, percaya diri, kerja sama antar pemeluk agama dan kepercayaan, anti perundungan dan kekerasan, persahabatan, ketulusan, mencintai lingkungan, dan melindungi yang kecil dan tersisih, dan tidak memaksakan kehendak. Misalnya, tidak memaksa diri untuk mengganti Pancasila.

\section{Karakter nasionalis-religius} merupakan cara berpikir bersikap dan berbuat yang menunjukkan kesetiaan, kepeduliaan, dan penghargaan yang tinggi, terhadap bahasa, lingkungan fisik, sosial budaya, ekonomi dan politik bangsa, menempatkan kepentingan bangsa dan negara di atas kepentingan diri dan kelompoknya. Sikap nasionalisme-religius merupakan perpaduan antara semangat nasionalisme dan keberagamaan. Pancasila dan ketuhanan sama sekali tidak berbenturan. Keduanya saling mengisi melahirkan kekuatan yang lebih yakni nasionalisme yang beragama dan semangat beragama yang nasionalis. Melalui sikap nasionalisme-religius, persatuan dan kesatuan bangsa menjadi lebih kuat dan kokoh.

Sastra merupakan ekspresi pengalaman dan citra estetis kehidupan manusia. Sastra menawarkan sebuah model kehidupan yang diidealkan. Religiusitas merupakan ciri utama sastra itu sendiri, karena sastra tumbuh dari hal yang bersifat religius. Atmosuwito (1989) menyatakan banyak sastra cenderung religius, sehingga sastra memiliki kandungan nilai moral dan agama (Syi'aruddin, 2018:3-11).

Karya sastra bertema nasionalisreligius perlu dijadikan bahan analisis sekaligus media internalisasi karakter bagi mahasiswa. Disadari atau tidak, pembaca akan mencoba mengembangkan karakter dirinya setelah membaca karya sastra. Pembaca akan menginternalisasikan nilai yang terkandung dalam karya sastra ke dalam dirinya. Oleh sebab itu, perkuliahan sastra berpotensi sebagai media penanaman karakter nasionalis- religius.

\section{METODE PENELITIAN}

Penelitian ini dilakukan dengan rancangan kualitatif-multidisipliner. Pendekatan penelitian ini mencakup pendekatan kebudayaan, ketahanan nasional, dan pembelajaran. Dari segi metodologis, penelitian ini dilakukan dengan menggunakan metode kualitatif (Miles dan Huberman, 1994). Sasaran penelitian ini adalah pendidikan karakter nasionalis-religius pada program studi Pendidikan Bahasa Indonesia Universitas Jember. Fokus penelitian pendidikan karakter ini berupa rencana pembelajaran, materi pembelajaran, proses belajar- 
mengajar, dan evaluasi pembelajaran pada era pelaksanaan kurikulum berbasis kompetensi sesuai KKNI.

Data penelitian ini dikumpulan dengan (a) metode dokumentasi, (b) metode observasi, dan (c) metode wawancara bebas-mendalam. Metode dokumentasi (Bogdan dan Biklen, 1982:97-100) digunakan untu memperoleh dokumen berupa kurikulum program studi, silabus matakuliah, materi ajar, dan alat evaluasi. Pelaksanaan metode dokumentasi ini dibantu dengan instrumen pemandu pengumpulan dokumen. Metode observasi dilakukan dengan bantuan panduan observasi yang digunakan untuk menggali data berupa informasi pelaksanaan pembelajaran pendidikan karakter di kelas perkuliahan. Pelaksanaan observasi berpedoman pada instrument panduan observasi.

Metode "indepth interview" (Milies dan Huberman, 1994) digunakan untuk menggali data berupa (a) pelaksanaan pembelajaran pendidikan karakter, (b) pelaksanaan evaluasi pendidikan karakter, dan (c) perilaku mahasiswa terkait rasa nasionalisme- religius dalam kehidupan sehari-hari dan bernegara saat kuliah dan pasca kelulusan. Pelaksanaan wawancara bebasmendalam dipandu oleh instrument panduan wawancara sesuai saran (Hunt, 2009) dengan modifikasi seperlunya.

Analisis data kualitatif penelitian ini menggunakan model analisis interaktif Miles dan Huberman
(1994) yang tahapannya pengumpulan data, (2) reduksi data, (3) penyajian data (temuan), (4) penyimpulan dan verifikasi temuan. Dalam kegiatan pengumpulan data dilakukan pengumpulan dokumen, observasi kelas, dan wawancara bebas mendalam dengan mahasiswa dan dosen. Dalam reduksi data dilakukan pengkodean data, seleksi, dan klasifikasi data. Dalam kegiatan penyajian data dilakukan pembuatan deskripsi karakter nasionalis-religius, penjelasan dan diskusi kasus, pembuatan abstraksi temuan, dan pengembangan bentuk sajian temuan dalam bentuk bagan, tabel, atau gambar sesuai kebutuhan. Dalam kegiatan penyimpulan dan verifikasi dilakukan kegiatan merumuskan temuan, mengecek validitas temuan dengan dibantu oleh konsultan pendidikan karakter, dan validasi temuan dengan konsultan ketahanan nasional. Pelaksanaan analisis data berpedoman pada instrument pemandu analisis data.

\section{PEMBAHASAN}

Pendidikan karakter nasionalisreligius untuk mahasiswa Pendidikan Bahasa Indonesia di Universitas Jember terdapat pada rencana pembelajaran yaitu pada unsur standard pembelajaran karakter, capaian pembelajaran, program studi, dan silabus matakuliah. Muatan nilai yang sama juga terdapat pada materi ajar dan proses pembelajaran. Pada bagian evaluasi pembelajaran masih kurang menekankan pendidikan karakter nasionalis-religius. Berikut ini 
dipaparkan hasil penelitian pendidikan karakter tersebut.

Muatan Karakter Nasionalisreligius dalam Rencana Pembelajaran Penanaman karakter nasonalisreligius tampak jelas dalam capaian pembelajaran yang ada pada kurikulum program studi. Karakter tersebut dibangun dengan mengambil langsung enam karakter umum lulusan yang digariskan dalam Peraturan Presiden Republik Indonesia Nomor 8 tahun 2012 tentang KKNI. Lulusan program Pendidikan Bahasa Indonesia S1 Universitas Jember harus memenuhi syarat seperti digambarkan dalam profil program studi sebagai berikut. (1) Bertaqwa kepada Tuhan Yang MahaEsa. (2) Memiliki moral, etika dan kepribadian yang baik di dalam menyelesaikan tugasnya. (3) Berperan sebagai warga negara yang bangga dan cinta tanah air serta mendukung perdamaian dunia. (4) Mampu bekerja sama dan memiliki kepekaan sosial dan kepedulian yang tinggi terhadap masyarakat dan lingkungannya. (5) Menghargai keanekaragaman budaya, pandangan, kepercayaan, dan agama serta pendapat/temuan original orang lain. (6) Menjunjung tinggi penegakan hukum serta memiliki semangat untuk mendahulukan kepentingan bangsa serta masyarakat luas.

Paparan tentang karakter dalam profil program studi menjiwai semua matakuliah yang disajikan dalam kurikulum prodi. Berangkat dari pandangan tersebut, maka sejumlah silabus matakuliah yang dibuat oleh dosen program studi ada yang tidak mencantumkan karakter "Bertaqwa kepada Tuhan Yang Maha Esa" karena dianggap redundansi, sudah diperkuat dalam silabus matakuliah Pendidikan Agama, dan telah didukung dalam kegiatan ekstra keagamaan tingkat fakultas dan universitas. Selanjutnya, rencana pendidikan karakter butir dua sampai dengan enam (2--6) diterjemahkan dalam butir-butir kompetensi yang harus dikuasai oleh mahasiswa setiap semester.

Penanaman karakter disiplin dimunculkan dalam pedoman persentase kehadiran. Misalnya, mahasiswa boleh ikut ujian akhir apabila memenuhi syarat kehadiran minimal $75 \%$ dan dosen boleh menguji apabila hadir $80 \%$. Gambaran karakter nasionalis-religius dalam rencana pembelajaran Pendidikan Bahasa Indonesia di Universitas Jember dinyatakan secara eksplisit dan implisit. Pernyataan secara eksplisit maksudnya tertulis secara formal dalam silabus matakuliah. Pernyataan implisit maksudnya di dalam silabus tidak dinyatakan secara formal tetapi karakater nasinalis-religius tersebut dipersepsi telah ada dengan mengikuti profil karakter yang ada pada kurikulum program studi.

Muatan Karakter Nasionalisreligius dalam Materi Ajar Materi pembelajaran Pendidikan Bahasa Indonesia pada umumnya memupuk rasa kebangsaan yang tinggi karena berisi tentang penghargaan dan kajian 
bahasa dan sastra Indonesia. Dari sejumlah materi matakuliah dapat ditemukan (a) prosa dan puisi Indonesia dan menulis kritik seni berdasarkan pendekatan tertentu, misalnya kritik pragmatik-religius; (b) prosa dan drama Indonesia, misalnya cerita Minak Jingga dan Calon Arang; (c) sastra multikultural dalam perspektif kultural dan agama; (d) aspek kejiwaan tokoh dalam prosa Indonesia dalam pandangan teori psikologi umum, psikologi analitis, psikologi sosial, dan psikologi agama; (e) pengkajian sastra lisan dan tradisi lisan berdasarkan teori kebudayaan dan teologi sebagai kekayaan budaya Nusantara; pembinaan dan pengembangan Bahasa Indonesia sebagai bahasa nasional dan bahasa negara sebagai rasa syukur kepada Tuhan Yang Mahaesa; (g) pengkajian aspek linguistik, fonologi, morfologi, sintaksis, semantik, wacana, pragmatik Bahasa Indonesia; dan (h) pengkajian teori-teori sastra struktural, semiotika, resepsi sastra, ekologi sastra, dan sastra Indonesia sebagai salah satu warga sastra dunia.

Topik-topik kajian dalam pembelajaran program studi secara eksplisit memiliki muatan untuk menguatkan karakter nasionalisreligius. Materi seperti itu akan mendorong pembelajaran yang sifat dinamis sekaligus mengembangkan rasa kebangsaan bagi mahasiswa untuk semakin mencintai Indonesia. Selanjutnya, rasa bangga akan bahasa dan sastra Nusantara itu secara eksplisit ataupun implisit mendorong mahasiswa mensyukuri nikmat itu kepada Tuhan, sehingga karakter religius akan menguat dalam diri mahasiswa. Dengan demikian karakter nasionalis-religius akan terbentuk pada diri mahasiswa.

Penanaman Karakter Nasionalisreligius dalam Proses Pembelajaran Internalisasi nilai nasionalis-religus ke dalam diri mahasiswa terjadi dalam proses pembelajaran dengan menerapkan diskusi kelas, sarasehan, bedah buku, praktik pementasan drama, musikalisasi puisi, praktik penelitian tradisi lisan ke lapangan, dan praktik menulis sastra. Kegiatan ini dilakukan dalam matakuliah kesastraan seperti Apresiasi Drama, Kritik Sastra, Teori Sastra, Sosiologi Sastra, Psikologi Sastra, Tradisi Lisan Indonesia, ekstrakurikuler dalam lomba baca puisi, dan kegiatan budaya berupa menulis puisi dan prosa.

Muatan Karakter Nasionalisreligius dalam Evaluas Implementasi pendidikan karakte nasionalis-religius pada Program Pendidikan Bahasa Indonesia di Universitas Jember amat kuat pada substansi rencana pembelajaran, materi, dan proses pembelajaran. Penanaman karakter ini belum kuat pada bagian penilaian. Pembinaan karakter nasionalis dan religius masih cenderung terpisah. Penilaian karakater religius yang menggambarkan ketakwaan kepada Tuhan Yang Mahaesa sudah ada tetapi tidak terpadu dengan rasa kebangsaan atau nasionalisme (nasionalis-religius 
atau religius-nasionalis). Fakta yang ada mengganti Pancasila dengan ideologi lain. Pernah ditemukan sat mahasiswa yang cenderung atheis karena tidak simpati kepada Islam karena keras. Menurut pengakuannya, kalau dipaksa harus beragama ia memilih Hindu, katanya lebih damai. Akan tetapi ia tetap memilih atheis dengan formalitas beragama Islam. Setelah ditelusur ternyata perilaku itu muncul karena dikhianati calon suaminya. la patah hati karena ditinggalkan tunangannya dan terlanjur "berhubungan akrab dan intim" dengan calon suaminya. Setelah lulus anak ini konon bekerja pada industri perbankan milik pemerintah Cina di Indonesia. Anak ini masuk dalam kategori faham nasionalis yang cenderung atheis dan mendesak untuk digeser ke paham nasionalis-religius.

Karakter religius mahasiswa ratarata kuat, akan tetapi ada kecenderungan dari 400 mahasiswa ada 3-4 atau 1\% mahasiswa yang berideologi Negara Islam. Fakta ini perlu disikapi dengan baik karena $1 \%$ ini bisa menular ke temantemannya lewat organisasi sosialkeagamaan. Kelompok ini masuk dalam kategori religius-radikal dan mendesak untuk digeser menjadi ke faham religius- nasionalis. Anak-anak kategori ini masuk dalam organisasi Islam-radikal yang telah dilarang oleh pemerintah.

Penilaian karakter nasional -religius secara terpadu sudah ada tetapi relatif terbatas. Misalnya, pada matakuliah tugas akhir berupa skripsi. Saat ujian skripsi selesai, pada bagian penutupan sidang, ketua penguji menyampaikan masukan kepada mahasiswa untuk (a) selalu menjaga nama baik agama, (b) selalu menjaga nama baik keluarga, almamater, dan negara, dan (c) bertindak lebih dewasa dan profesional dalam menyelesaikan segala persoalan sebagai cermin kesarjanaannya. Saran dan evaluasi ini disampaikan untuk seluruh mahasiswa yang selesai ujian dan lebih ditekankan pada mahasiswa yang terindikasi radikal atau "coba-coba atheis". Pada contoh kasus ini penilai karakter nasionalis- religius dilaksanakan secara terpadu.

\section{SIMPULAN DAN SARAN}

Implementasi pendidikan karakter nasionalisme-religius dalam mata kuliah untuk mahasiswa Pendidikan Bahasa Indonesia masih terbatas pada rencana pembelajaran, materi ajar, dan proses pembelajaran. Pada bagian evaluasi hasil belajar, nilai religius telah masuk dalam aspek penilaian tetapi tidak terpadu dengan nilai nasionalisme. Sebaliknya, penilaian karakter nasionalis telah dilakukan, tetapi tidak terpadu dengan karakter religius.

Sekitar 1\% mahasiswa pendidika Bahasa Indonesia masih menganut faham religius-Islam radikal, dan sekitar 0,025 \% mahasiswa berfaham nasionalis-"coba- coba atheis" karena frustrasi. Fakta ini mengabarkan bahwa masih terdapat mahasiswa yang nasionalis tetapi coba- coba 
atheis dan ada mahasiswa yang religius tetapi radikal.

Agar dua gejala negatif tersebut tidak berkembang perlu dilakukan upaya-upaya khusus. Saran yang dapat diberikan berdasarkan hasil kajian ini adalah sebagai berikut. Sebaiknya perangkat pembelajaran disiapkan untuk memformulasikan pencapaian karakter sampai tahap penilaiannya, karena karakter nasionalis-religius bukan hanya capaian pembelajaran program studi tetapi juga capaian pembelajaran institusional yakni Universitas Jember. Semua matakuliah baik kebahasaan, kesastraan, dan pembelajaran bahasa dan sastra Indonesia, sebaiknya lebih menekankan pencapaian karakter yang diwujudkan dalam sikap atau perilaku nyata dalam kehidupan di kampus dan masyarakat. Perlu dibicarakan secara melembaga bahwa karakter nasionalis -religius atau religius-nasionalis menjadi syarat ketat untuk lulus dari Universitas Jember bagi setiap WNI sehingga tidak ada alumni yang "coba-coba atheis" atau religius-radikal.

\section{DAFTAR RUJUKAN}

Satata, S., Suswandari, D., \& Suhardjono, D. W. (2012). Bahasa Indonesia; Untuk Penulisan Akademik di Perguruan Tinggi. Jakarta: Mitra Wacana Media.

Suladi. (2014). Paragraf; Seri Penyuluhan
Bahasa Indonesia. Jakarta: Badan Pengembangan dan Pembinaan Bahasa. Atmosuwito, Subijantoro.1989. Perihal Sastra dan Religiusitas dalam Sastra. Bandung: Sinar baru BBC News. 2018. "Masjid di Lingkungan Pemerintah Terpapar Radikalisme, 17 Masuk Kategori Parah" dalam BBCNews 18 November 2018. Dari bbc.com diakses 20 November 2018.

BIN.2017. "BIN: 39 Persen Mahasiswa Terpapar Radikalisme" dalam Liputan6.com 29 April 2018. Diakses 5 November 2018.

Burhanudin, Nunu. 2015. "Konstruksi Nasionalisme Religius: Relasi Cinta dan Harga Diri dalam Karya Hamka" dalam EPISTEME' : Jurnal Pengembangan Ilmu Keislaman. Vol. 10 No. 2 2015. http://ejournal.iaintulungagung.ac.id/index.php/e pis/ article/ view/87

Detiknews. 2018. “BIN Jelaskan 41 Masjid

Pemerintah

Lingkungan Radikalisme" Terpapar dalam Detiknews 18 November 2018. Dari detik.com diakses 20 November 2018.

Daja, Soenarjati. 2000. Kritik Sastra Feminis Sebuah Pengantar. Jakarta : Gramedia Pustaka Utama. Endraswara, Suwardi. 2003. Membaca, Menulis, 
Mengjarkan Sastra. Yogyakarta: (PPGI) DIY.

Hunt, Marjorie. 2003. The Smithsonian Folklife and Oral History Interviewing Guide. Wasington DC: The Smithsonian Institutions.

Kayudha, 2013, Upaya Memajukan Ketahanan Nasional di dalam Aspek Sosial Budaya. Dalam http://kayudha.blogspot.com/2 013/05 /cara-meningkatkanpertahanan- nasional.html (Diakses 9 November 2018).

Kemendikbud.

2017.

"Penguatan

Pendidikan Karakter" dalam https://www.kemdikbud.go.id/ main/b log/2017/07/ penguatan-pendidikankarakter-jadi-pintu-masukpembenahan-pendidikannasional. Diakses 17 Oktober 2018.

Kompas.com. $2018 . \quad$ “Dedi Mulyadi

Usulkan Pemecatan PNS AntiPancasila" dalam KOMPAS.com di regional.kompas.com November

2018. Diakses 20 November 2018. Lickona, Thomas. 2015. Ecucating For

Character (Mendidik untuk Membentuk Karakter). Diterjemahkan oleh Juma Abdu Wamaungo. Jakarta: Penerbit Bumi Aksara.
Miles, Matthew B. dan Huberman, A.

Michael. 1994. Qualitative Data Analysis. London: Sage Publications. Presiden RI. 2012. Peraturan Presiden Republik Indonesia Nomor 8 Tahun 2012 Tentang Kerangka Kualifikasi Nasional Indonesia. Diundangkan di Jakarta pada tanggal 17 Januari 2012 Menteri Hukum dan Hak Asasi Manusia Republik Indonesia.

$\begin{array}{ll}\text { Puguh, } & \text { D.R,. }\end{array}$ Membangun Masyarakat Madani Berbasis Kearifan Lokal. http://komunitas.wikispaces.co $\mathrm{m} /$ file/ view/ORMAS+KEAGAMAAN+DA $L A M+P$ EMBERDAYAAN+POLITIK+MASY ARAKA T+MADANI.pdf (Diakses 31 Desember 2009).

Republika.co.id. 2018. "Masjid Radikal dan PNS Anti Pancasila, Bansoet: Kecolongan" dalam Republika.co.id 20 November 2018 diakses 20 November 2018.

Soedjatmoko. 1986. Dimensi Manusia dalam Pembangunan. Jakarta: LP3EST

Sukatman. 2009. Butir-butir Tradisi Lisan Indonesia. Yogyakarta: Penerbit LaksBang.

Syi'aruddin, Mohammad Anwar. 2018. 
Sastra dan Agama: Transformasi Nilainilai Ajaran Islam dalam Karya Sastra. Diakses 14 Desember 2018 dari https://www.academia.edu/19 076476/Sastra_dan_Agama_Tr ansformasi_Nilainilai_Ajaran_Is lam_dalam_Karya_Sastr a?auto=download.
Taufiq, Akhmad. 2017. Sastra Multi Kultur: Konstruksi Identitas dan Praktik Diskursif Negara dalam Perkembangan Sastra Indonesia. Malang: Penerbit Beranda. Widja, I Gde. 2002. Menuju Wajah Baru Pendidikan Sejarah. Yogyakarta: Lappera Pustaka Utama. 